\title{
A pesquisa em espaços de educação não formal em ciências na Região Norte: o caso do Bosque da Ciência
}

The research in informal learning of sciences in the North Region: The case of the science forests

Saulo Cezar Seiffert Santos ${ }^{1}$ Marcia Borin da Cunha

\section{Resumo}

A pesquisa em espaços de educação não formal em ciências tem crescido no Brasil. Na Região Norte do Brasil muitos dos museus de ciências situam-se na floresta amazônica e possuem características próprias. Buscamos neste contexto realizar um estudo qualitativo bibliográfico sobre o Bosque da Ciência na cidade de Manaus-AM, análogo ao museu de ciências. Consultamos o Google Acadêmico e o site de um grupo de pesquisa em espaços não formais no Amazonas no período de 2010-2018. Localizamos 24 trabalhos completos publicados em revistas e anais. Os trabalhos sobre o Bosque são normalmente de descrição do espaço e de sequência didática, e possuem enfoque ontológico, com observação dos seres vivos e uso de painel informativo, representação fiel da natureza, com interação minds-on e heards-on, com pressupostos empiristas e construtivistas para a área ambiental e ensino de ciências. Acreditamos que futuras pesquisas tendem a se dirigir a valorização da experiência humana e ao sócioconstrutivismo.

Palavras chave: divulgação científica; educação não formal; Bosque da Ciência.

\section{Abstract}

Research in informal learning of science has grown in Brazil. In the Northern Region of Brazil many of the science museums are located in the Amazon forest and have their own characteristics. We searched in this context to perform a qualitative bibliographic study on the Forest of Science in the city of Manaus-AM, analogous to the science museum. We consulted the Google Scholar and the site of a research group in non-formal spaces in Amazonas in the period of 2010-2018. We have located 24 complete papers published in journals and event annals. The works on the Grove are usually descriptive of space and didactic sequence, and have ontological focus, with observation of living beings and use of information panel, faithful representation of nature, with minds-on interaction and heardson, with empiricist assumptions and constructivists with environmental area and science education. We believe that future research tends to focus on the valuation of human experience and socio-constructivism.

Keywords: Popularization of science; informal learning; Forest of Science.

\footnotetext{
${ }^{1}$ Universidade Federal do Amazonas | sauloseiffert@ufam.edu.br

${ }^{2}$ Universidade Estadual do Oeste do Paraná | borin.unioeste@gmail.com
} 


\section{Introdução}

A divulgação científica tem como função partilhar o conhecimento produzido na Ciência e pela Ciência ao grande público, independente do conhecimento sobre Ciência que esse público detém (BUENO, 2010).

A divulgação científica pode acontecer nos denominados "Espaços de educação não formal". Mesmo que a definição de espaços como formal, não formal e informal não compartilhe de consenso na literatura em educação/ensino. Esses espaços podem ser entendidos como um ambiente que não pertencem à escola, podendo esse ambiente ser institucionalizado, pertencente a uma organização ou instituição, como o caso dos Centros de Ciência e Museus e seus congêneres, como zoológico, jardim botânico, entre outros; ou não institucionalizado, como praças, parques e ambientes abertos ao público (JACOBUCCI, 2008).

Sem a pretensão de fechar uma definição para o termo "não formal" ou apresentar uma revisão exaustiva, sintetizamos a tipologia do não formal (acompanhada pelas designações formal e informal ${ }^{3}$ ) já estudado por muitos pesquisadores na perspectiva de educação, aprendizagem, espaço e programa (sugerimos algumas pesquisas com a utilização desses termos: MARANDINO et al, 2004; ESHACH, 2007; STOCKLMAYER; RENNIE; GILBERT, 2010; QUEIROZ et al, 2011; MARQUES; FREITAS, 2017). Nesses trabalhos podemos realçar que a "perspectiva de educação" se remete à Organização das Nações Unidas para a Educação, a Ciência e Cultura (UNESCO), do ponto de vista governamental com políticas educativas; a "perspectiva da aprendizagem" vieses de pesquisadores em museus de ciências e tecnologia, que exploram as experiências dos visitantes na qualidade de excursão de estudantes, ou visitante voluntário, normalmente vinculado ao desenvolvimento de capacidades; a "perspectiva dos espaços" se foca nos ambientes e recursos fora da escola ou experiências fora da sala de aula, e o que esses ambientes podem oferecer para o enriquecimento cultural; na "perspectiva de programa" está relacionado à cursos ou atividades programadas para formação complementar à escola ou cultura, como curso de férias, formação em ciência e tecnologia, entre outros cursos.

Ao nosso ver, entendemos e definimos que o conceito de espaço de educação não formal em ciências, como o local/ambiente (físico ou virtual) potencialmente estruturado (com artefatos e proposta didática explícita ou implícita) para o ato educativo intencional mediado (ou em colaboração) com a possibilidade da mediação de um formador responsável aos aprendizes (escolares ou não), sendo que este responsável não está necessariamente vinculado à instituição ao qual realiza a visita (se for o caso de espaço institucional) para desenvolver o processo de ensino e aprendizagem.

Um exemplo dessas pesquisas educativas, em relação ao tipo de programa pedagógico de museus científicos pode oferecer, segundo França, Acioly-Régnier e Ferreira (2011, p. 3) apresentam Montpetit (1998) que orienta esses programas nos enfoques ontológico (real,

\footnotetext{
${ }^{3}$ Com propósito de distinguir o "não formal" do "formal" e "informal" é importante entender que não há nomenclatura consensual. Normalmente ao se inferir ao termo formal à atividade escolar (conteúdo programático, avaliação compulsória, certificada e chancelada pelo Estado, entre outras características), e o termo informal é associado a aprendizagem livre e comunitária ocorrida na convivência espontânea (família, igreja, comunidades de práticas, etc.). Esses temos qualificadores podem fazer relação com os termos educação, ensino, aprendizagem, espaço, entre outros. Dependendo do quadro teórico e problema elencado.
} 
ou elementos naturais), histórico (narrativa social) e epistemológico (narrativa do discurso científico) (Quadro 1).

Quadro 1: Enfoques dos programas pedagógicos dos museus científicos.

\begin{tabular}{c|c|c|c}
\hline Enfoques & Ontológico & Histórico & Epistemológico \\
\hline $\begin{array}{c}\text { Objeto de } \\
\text { apresentação }\end{array}$ & $\begin{array}{c}\text { Espécie } \\
\text { biológica }\end{array}$ & Artefatos históricos & Experiências científicas \\
\hline Realidade & $\begin{array}{c}\text { Natural } \\
\text { (Coleções vivas) }\end{array}$ & Sócio-histórica da C\&T & $\begin{array}{c}\text { Curiosidade e a construção } \\
\text { do conhecimento científico }\end{array}$ \\
\hline Exemplos & $\begin{array}{c}\text { Parques, } \\
\text { Jardins }\end{array}$ & $\begin{array}{c}\text { Museus de abordagem } \\
\text { antropológica, etnográfica, } \\
\text { nacional e C\&T }\end{array}$ & $\begin{array}{c}\text { Museus de Ciências, Salas de } \\
\text { laboratórios, anatomia, etc. }\end{array}$ \\
\hline
\end{tabular}

Fonte: Adaptado de França, Acioly-Régnier e Ferreira (2011, p. 3).

Espaços de educação não formais são interessantes para crianças em relação ao enfoque ontológico e, para os adolescentes (ensino médio), com enfoque epistemológico.

Por outro lado, por exemplo, a pesquisa comunicacional para museus de Ciências, apresentamos Aragão (2013), em sua pesquisa sobre concepções de educação não formal, acrescenta análises a partir da museografia e sociologia da ciência, tais como: tipos de display, formas de representação e interatividade (Quadro 2).

Quadro 2: Categoria de análise e grandes grupos.

\begin{tabular}{l|l|l}
\hline Tipos de Display & Formas de Representação & Interatividade \\
\hline Objeto/artefato & Fiel à natureza & Hands-on \\
\hline Painel 2D ou 3D & Objetividade mecânica & Minds-on \\
\hline Monitor & Avaliação instruída & Heards-on \\
\hline & Fonte: Aragão $(2013,0.64)$. &
\end{tabular}

Display ou ação de iniciação acontece por meio da análise da experiência educativa, pois o foco está mais no display-objeto ou no display-informação, quando se considera a forma e o conteúdo. No caso, observam-se os objetos de exposição, painel de informação 2D e 3D (banners) e o monitor (quando ocorre).

A interação com o visitante: hands-on (ou a resposta por manipulação, por exemplo, aos artefatos), minds-on (interação mental, ou questões vistas na exposição que relaciona com o cotidiano, ou com outras vivências), hearts-on (emocional, no caso dá prioridade às identidades coletivas relacionando-as com fatores culturais, fazendo-as sensível ao visitante). As últimas podem ser mediadas por display eletrônico ou monitor.

Em relação à representação científica: fiel à natureza (objetividade, ou representações de reais e fiéis dos objetos ou fenômenos, por exemplo, os fósseis), objetividade mecânica (ou a representação do real, como fotos), avaliação instruída (a interpretação dada pelo especialista, ou sua leitura dos fatos, como narrativa de terceiro).

Somando a esses conceitos podemos falar na análise pedagógica referente ao eixo epistemológico e psicológico. No eixo epistemológico as exposições podem variar no polo do empirista-indutivista ao idealista-racionalista (HEIN, 2006). Por outro lado, no eixo 
psicológico educacional varia na ideia de conhecer por incremento (oportunizar informação), ou seja, orientação comportamental; e orientação construtivista para o sujeito construtor do conhecimento (HEIN, 2006).

No Brasil os espaços de educação não formal em ciência têm sido bastante pesquisados (SEIFFERT-SANTOS; CUNHA, 2018), e em cada região geográfica esses espaços colaboram nas suas características aos diferentes temas e assuntos, os quais dialogam com a educação escolar. A nosso ver, a Região Norte possui características específicas e diferenciadas em relação ao espaço geográfico e os tipos de instituições de educação não formal em ciências. Todavia, caso observado uma instituição educativa não formal, quais seriam essas características?

Posto isso, o nosso objetivo é analisar um espaço institucional de divulgação científica da Região Norte denominado de Bosque da Ciência (lê-se BC, doravante) administrado pelo Instituto Nacional de Pesquisa da Amazônia (lê-se INPA, doravante), em Manaus/AM, a partir de elementos de comunicação e museográficos sobre sua potencialidade educativa.

\section{Museus de Ciências na Região Norte do Brasil}

A região Norte do Brasil apresenta o menor número de instituições, com somente 11 Museus e Centros de Ciências entre 268 cadastrados no guia Museus e Centro de Ciências presentes no "Catálogo Centro e Museus de Ciências do Brasil 2015" da Região Norte (ABCMC, 2015) situados nos estados do Amapá, Amazonas e Pará. Ilustramos alguns exemplos: Centro de Pesquisa Museológica - Museu Sacaca (Macapá/AP); Bosque da Ciência/INPA (Manaus/AM); Museu Zoobotânico Emílio Goeldi (Belém/PA). Instituições com ênfase nas ricas exposições sobre a biodiversidade e elementos antropológicos amazônicos.

Uma observação importante sobre a história dos museus de ciências brasileiros, Borges, Silva e Dias (2015) apontam que sua origem está associada ao movimento internacional de alfabetização científica no contexto de Guerra Fria, em que foram criados os Centros de Ciências (CECI): Recife/PE, Porto Alegre/RS, Salvador/BA, São Paulo/SP, Belo Horizonte/MG e Rio de Janeiro/RJ. Esses centros originaram ou colaboraram, em sua maioria, com instituições, grupos de pesquisadores e educadores formando os atuais museus de Ciências nas diferentes regiões brasileiras.

Não ocorreu financiamento para a formação de grupos de pesquisadores sobre educação em ciências e divulgação científica até recentemente na Região Norte. Desta forma, muitos dos museus de ciências e seus congêneres surgiram tardiamente e possuem origem diversificadas e não necessariamente relacionada aos grupos de pesquisa ou a grupos de educadores. Situação diferenciada das outras regiões do país que receberam colaboração com a existência dos CECl's (Centros de Ciências).

\section{Procedimento metodológico}

A pesquisa é caracterizada como abordagem qualitativa por meio de uso do método bibliográfico (FLICK, 2013). Utilizamos a base de dados do Google Acadêmico empregando o termo para busca "Bosque da Ciência" nos campos de título, resumo e palavras-chave. Comparamos como parâmetro complementar com as pesquisas presentes no site do Grupo de Estudo e Pesquisa Educação em Ciências em Espaços Não Formais da Universidade do 
Estado do Amazonas, GEPECENF/UEA. Esse é um grupo que pesquisa sobre a temática de "Espaços Não Formais Amazônicos" desde 2004. Foram selecionados artigos completos de eventos e revistas no período de 2010-2018. Focamos nas atividades realizadas ou enunciadas sobre as estações do BC.

O BC foi selecionado por possuir um programa de divulgação científica institucional relativamente antigo, um espaço estruturado de visitação para público diversos e apresentar um número de trabalhos possível de verificação na base de dados proposta. Local no qual foi possível realizar visita e registro por fotos das estações de visitação pública.

Os resultados apresentam as informações gerais do BC, enfoque de apresentação, elementos museográficos, aproximações de pressupostos epistemológicos e psicológicos sobre educação em espaços não formais em ciência.

\section{Resultados}

Encontramos 24 trabalhos, sendo 11 artigos de revistas e 13 trabalhos completos em anais. Sendo os trabalhos em educação em ciência e/ou educação ambiental.

Houveram 3 ensaios, 8 relatos de experiência e 13 pesquisas empíricas. Dois trabalhos foram utilizados métodos de entrevistas com sujeitos relacionados ao BC, no qual não foi tratado diretamente sobre o espaço não formal.

Os trabalhos destacaram a fundação do INPA em 1954, e a criação do BC em 1995, com um espaço físico de 13 hectares, localizado na Zona Centro-Leste de Manaus/AM, destacando-o como espaço socioeducativo para promoção da divulgação científica e educação ambiental para visitantes da comunidade e das escolas.

A instituição informa em seu site ${ }^{4}$ que seus objetivos são: desenvolver e promover o programa do INPA para difusão tecnológica, científica e de inovação; oferecer à população local, uma opção de lazer que possa contribuir para sua educação cultural e ambiental.

Em 1999 a criação do Programa Circuito da Ciência ligado as atividades de extensão baseada na aprendizagem pela exibição e ludicidade para estudantes da educação infantil e fundamental, com atividades variadas como o uso dos recursos hídricos, pirogravuras recicladas, saúde bucal, nutrição e rotulagem de alimentos, invertebrados terrestres, mamíferos aquáticos, vida do gavião real, malária e dengue e, tecnologias sociais das abelhas e sapos, entre outros.

Verificamos que as pesquisas foram realizadas, na maior parte, pelo Programa de PósGraduação em Educação e Ensino de Ciências da Amazônia da Universidade Estadual do Amazonas e, como pesquisador mais frequente o Dr. Augusto F. Terán, tratando do potencial educacional do espaço não formal. Outra pesquisa em um único trabalho realizado pelo Laboratório de Psicologia e Educação Ambiental do INPA, desenvolveu o Projeto Pequenos Guias do Bosque da Ciência, coordenada pela Dra. Maria I. G. Higuchi, que tratou de percepção socioambiental.

No total de trabalhos sobre o BC foram citadas 17 estações oferecidas para visita, a saber 103 menções relativas. Sendo possível diversas combinações de estações de acordo

\footnotetext{
${ }^{4}$ Disponível em: http://bosque.inpa.gov.br/bosque/index.php/obj
} 
com o interesse. Organizamos as estações na tabela 1, na ordem usual de visita e número de frequência relativa:
1. Trilhas Educativas ( $n=15)$,
2. Tanques de Peixe-Boi $(n=14)$,
3. Viveiro das Ariranhas $(n=10)$,
4. Casa da Ciência $(n=15)$,
5. Ilha da Tanimbuca $(n=8)$,
6. Biblioteca $(n=5)$,
7. Recanto dos Inajás ( $n=13)$,
8. Condomínio das Abelhas ( $n=3)$,
9. Abraço da Morte $(n=6)$,
10. Paiol da Cultura $(n=2)$,
11. Orquidário e Bromeliário $(n=1)$,
12. Trilha suspensa $(n=5)$,
13. Lago Amazônico $(n=9)$,
14. Viveiro dos Jacarés $(n=8)$,
15. Casa da Madeira $(n=5)$,
16. Tendas do Circuito da Ciência $(n=5)$,
17. Centro de Estudos de Quelônios da
Amazônia (CEQUA) $)^{5}(n=3)$.

A consulta detalhada das estações do BC pode ser acessada em Rocha e Fachín-Terán (2010, 2014). Algumas dessas estações estão dispostas num mapa esquemático do BC (Fig. 01):

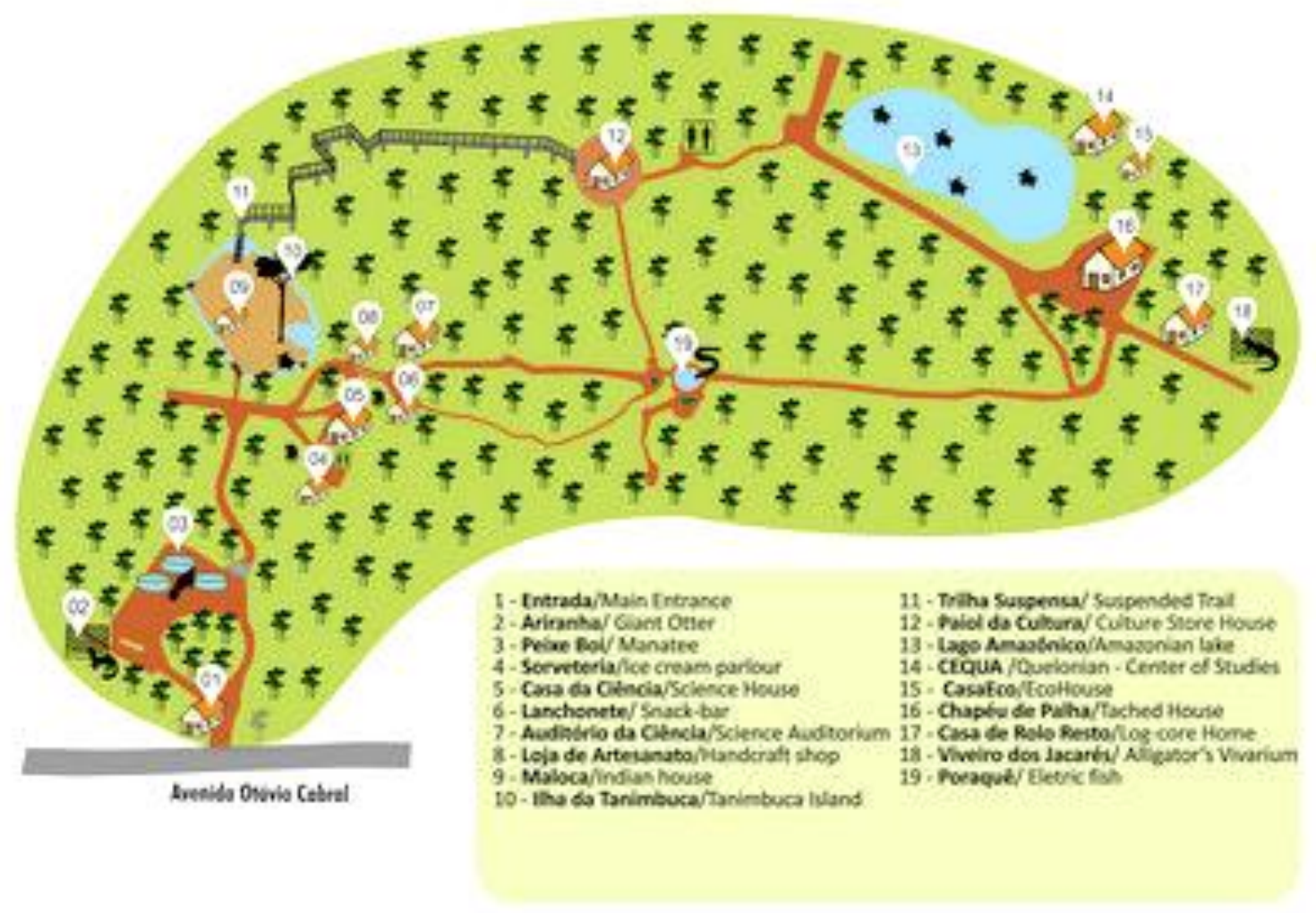

Fig. 01: Mapa esquemática do BC. Fonte: http://bosque.inpa.gov.br

\footnotetext{
${ }^{5}$ O Centro de Estudos de Quelônios da Amazônia (CEQUA/INPA) inaugurado em 2015 possui administração autônoma ao BC, contudo, possui uma área de visitação. Na oportunidade de está localizado ao lado do Lago Amazônico, muitos aproveitam para fazer visitação como parte do itinerário do BC. Disponível em: https://www.facebook.com/cequamanaus/
} 
Nas Figuras 2 a 11 apresentam algumas imagens das estações de visita do BC.

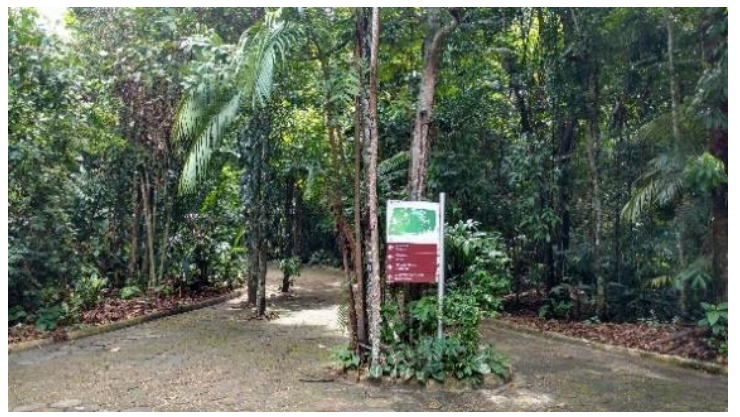

Fig. 2: Trilhas Educativas (entrada do BC).

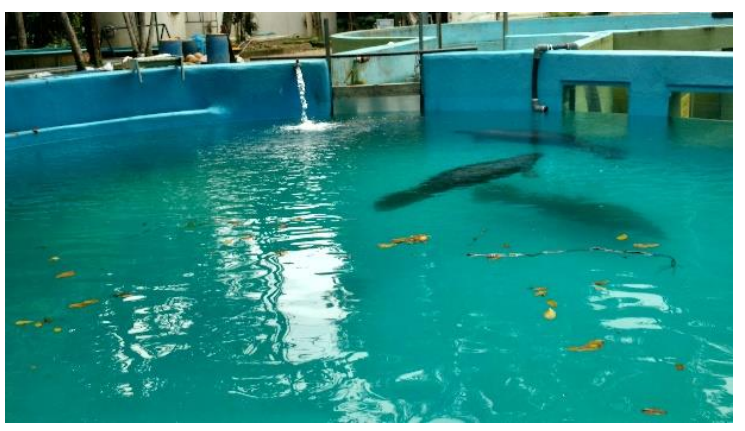

Fig. 4: Peixes-boi (Trichechus inunguis).

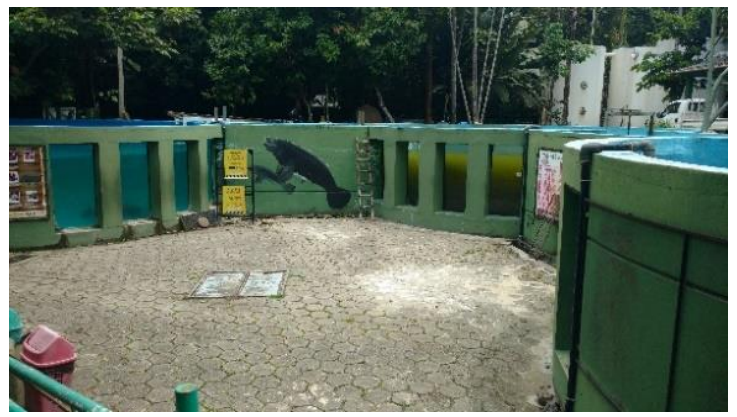

Fig. 3: Tanques de Peixe-Boi.

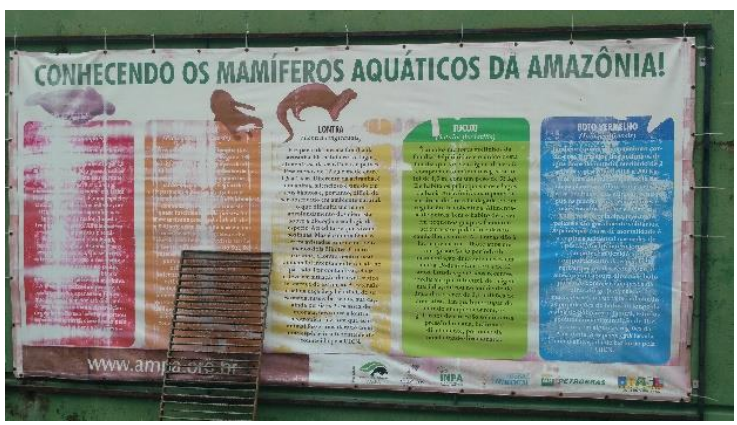

Fig. 5: Placa informativa dos mamíferos aquáticos.

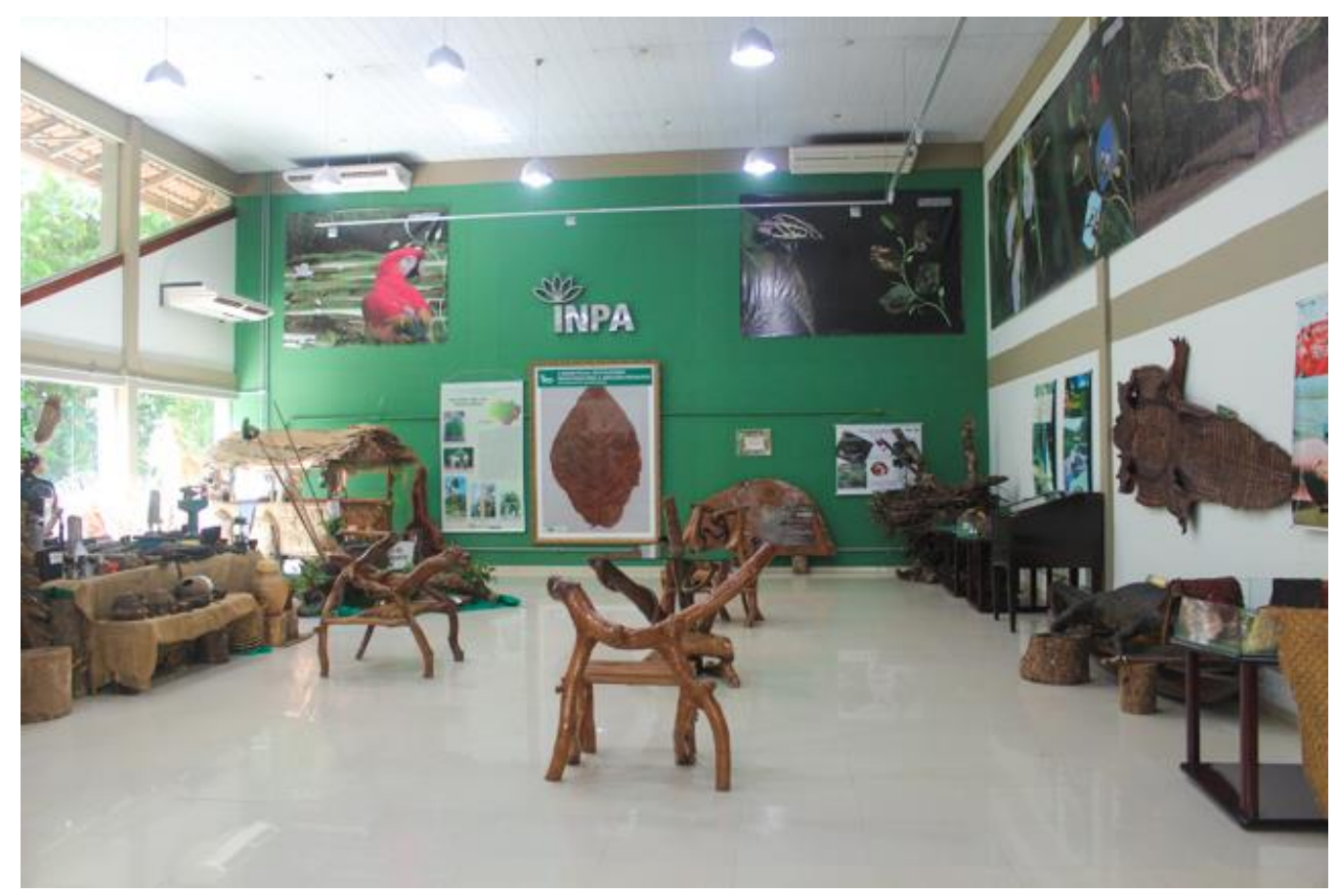

Fig. 06: Interior da Casa da Ciência. Fonte: Dayana Souza (2017). 


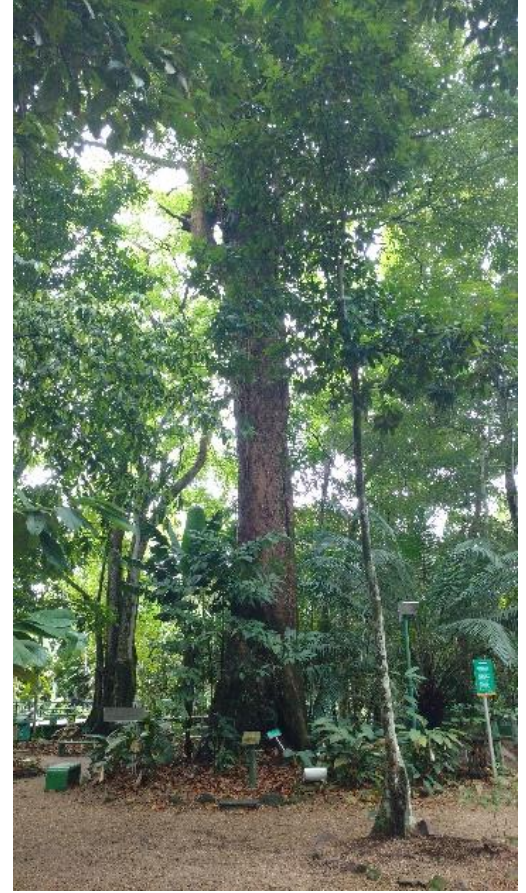

Fig. 7: Tanimbuca na ilha da tanimbuca (Buchenavea huberii).

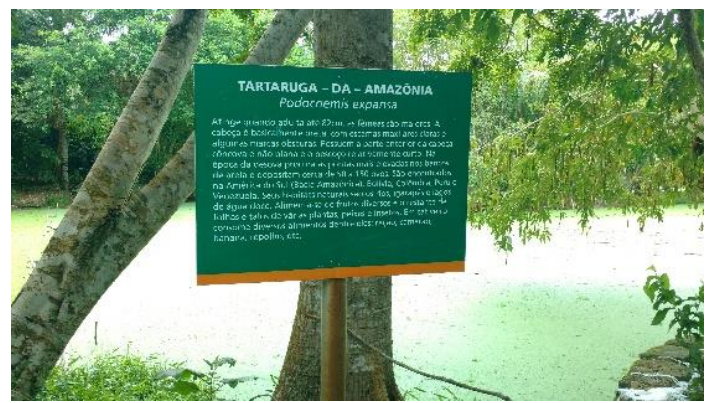

Fig. 9: Placa informativa sobre a Tartaruga da Amazônia no Lago Amazônico.

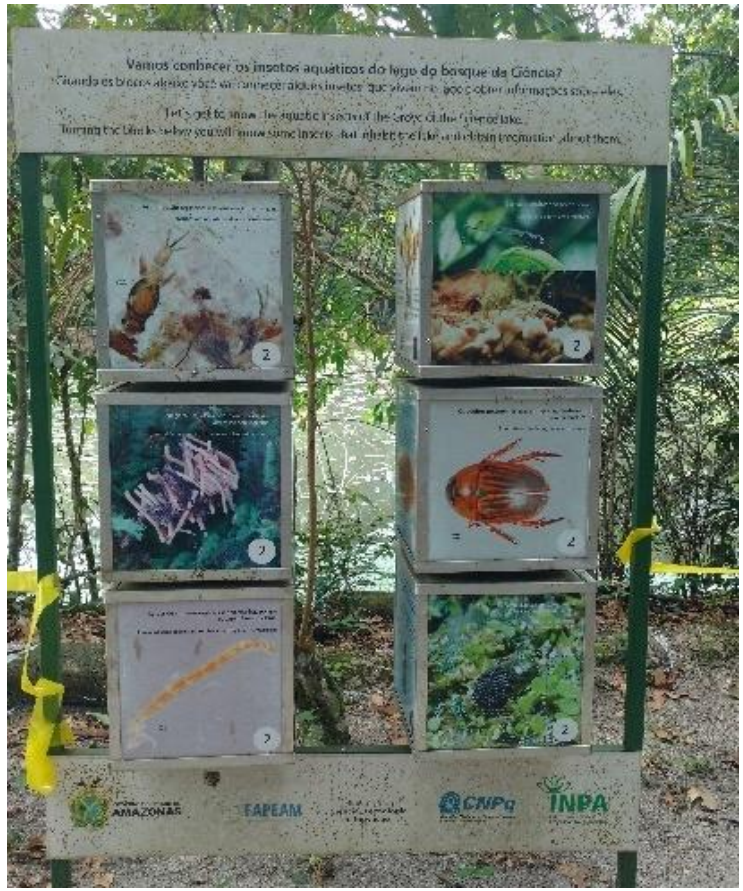

Fig. 8: Lago Amazônico - Cubos sobre Insetos aquáticos.

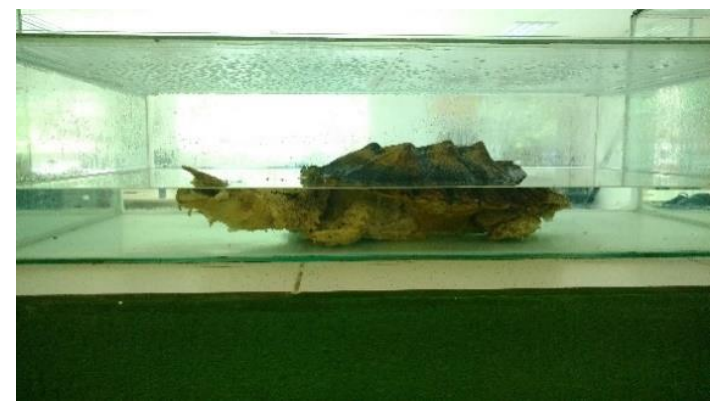

Fig. 10: CEQUA - Mata-mata (Chelus fimbriata).

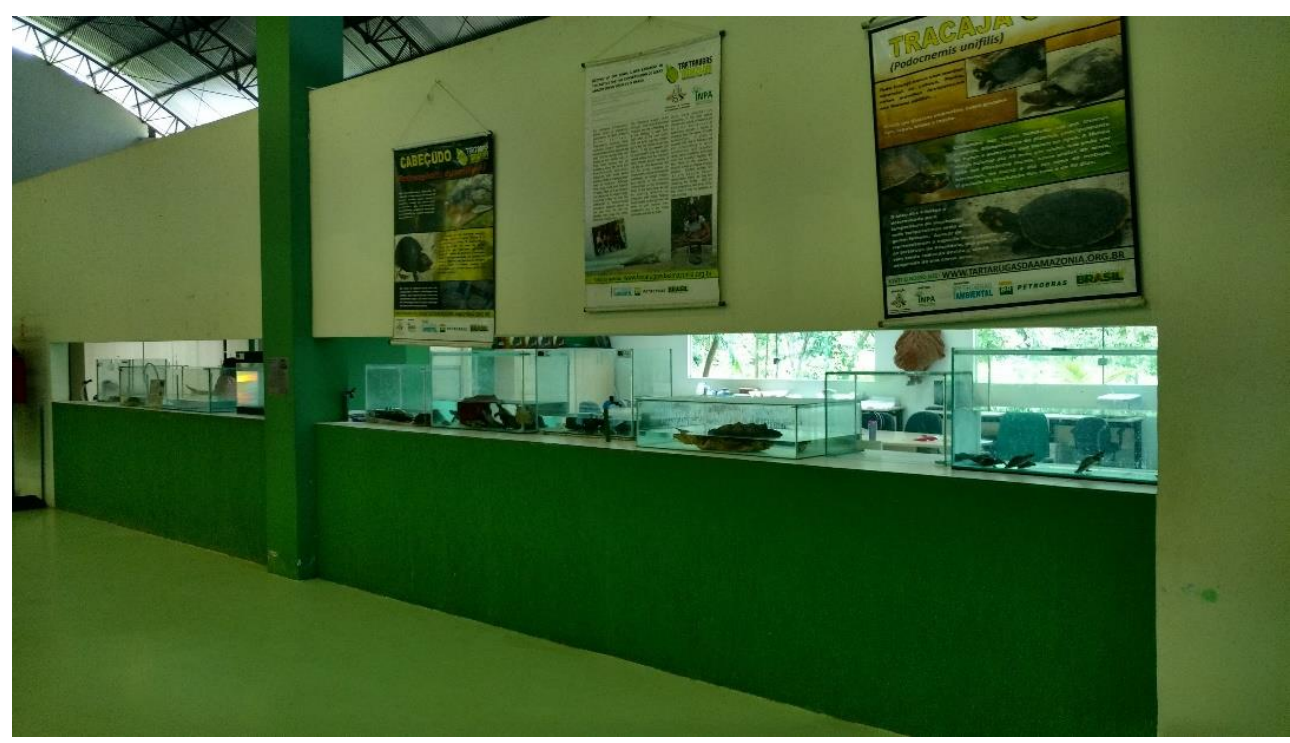

Fig. 11: Estante de aquários com quelônios amazônicos no CEQUA. 
Percebemos no processo de leitura e visita as estações que normalmente do ponto de vista comunicacional educativa, destacou-se o enfoque ontológico, pois apresentam os organismos e coleções de animais e vegetais conservados como artefatos de saber científico.

O enfoque ontológico por meio dos organismos vivos é apropriado ao convite de uma imersão do visitante no ambiente, e apreender por percepção a vida nos seus movimentos, formas, cores e sons. O BC é um fragmento florestal com seus recursos minerais e biológicos em interação no qual está estruturado e organizado para receber visitas. Sua riqueza cultural são os próprios elementos naturais, os organismos vivos e livres no ambiente (árvores, arbustos, palmeiras, plântulas, insetos, anfíbios, répteis, mamíferos e aves) são facilmente observados, e acrescentam-se os organismos conservados (caixas entomológicas, peixes empalhados, folhas "exsicata", entre outros) presentes na Casa da Ciência e CEQUA.

As três estações mais citadas são o tanque do peixe-boi, recanto das ariranhas e o recanto das inajás, fora as trilhas (que é ricamente ocupada por vegetação, com placas informativas), em que os animais são os protagonistas, os peixes-boi, as ariranhas (Pteronura brasiliensis) e os poraquês (peixe-elétrico, Electrophorus electricus) num tanque junto a tambaquis (Colossoma macropomum) e plantas aquáticas diversas com a presença de várias inajás (palmeira, Attalea maripa).

Ressaltamos que na Casa da Ciência deteve características mistas de enfoque epistemológico e ontológico, devido aos artefatos de origem ribeirinha que remete ao histórico do ciclo econômico da borracha no final do século XIX e início do século XX; e os banners sobre o destaque de alguns organismos amazônicos, como gavião real (Harpia harpia).

Os artefatos são apresentados com placas informativas para o auto percurso, ou com acompanhamento dos monitores mirins e/ou professores; sendo muitos objetos fieis a natureza; as atividades da Casa da Ciência e o Circuito da Ciência apresentam objetividade mecânica e avaliação instruída por meio de banners e dos monitores; a interação foram predominantemente mind-on e heard-on, contudo, há locais em que há árvores e elementos florestais disponíveis ao toque para percepção de textura, olfato e visualização conformando um estimulo próximo ao hands-on.

Normalmente os artefatos culturais estão acompanhados de placa informativa ${ }^{6} \mathrm{com}$ nome científico, nome popular, e uma breve descrição informativa sobre dados ecológicos, reprodutivos e morfofisiológico. A linguagem informativa utiliza a norma da língua portuguesa com palavras de uso comum (informação nutricional e distribuição geográfica, por exemplo) e com uso científico (nomes científicos e descrição do organismo).

Entendemos que essas placas possuem o papel mediador de informar e/ou transpor da experiência da percepção a uma associação abstrata ou empírica. Contudo, ao nosso ver, as informações são de perfil adulto na maioria das estações, com exceção de algumas placas e banners do tanque do peixe-boi e do CEQUA.

\footnotetext{
${ }^{6}$ No BC possui diversas placas: transito, identificação, indicação de sentido, entre outras. Essas placas estão em boas condições. Contudo, no que tratamos a analisar foram as placas informativas dos artefatos culturais de divulgação científica.
} 
Para exemplificar a nossa observação descrevemos a informação da placa informativa sobre a Tartaruga da Amazônia no Lago Amazônico (Fig. 9):

\section{TARTARUGA-DA-AMAZÔNIA \\ Podocnemis expansa}

Atinge quando adulto até $82 \mathrm{~cm}$, as fêmeas são maiores. A cabeça é basicamente preta, com escamas maxilares claras e algumas marcas obscuras. Possuem a parte anterior da cabeça côncava e não plana e o pescoço relativamente curto. Na época da desova procura as pontas mais elevadas nos bancos de areia e deposita cerca de 50 a 150 ovos. São encontrados na América do Sul (Bacia Amazônica), Bolívia, Colômbia, Peru e Venezuela. Seus habitat naturais são os rios, igarapés e lagos de água doce. Alimenta-se de frutos diversos e o resto de folhas e talos de várias plantas, peixes e insetos. Em cativeiro consome diversos alimentos dentre eles: ração, camarão, banana, repolho, etc. (Placa da Figura 9).

Neste ambiente, o Lago Amazônico, há um lago artificial com tartarugas de diversas espécies, insetos e peixes, com vegetação ciliar e presença de animais que utilizam o ambiente transitoriamente, como muitas espécies de aves.

A descrição busca ser clara e não equivocada, não confusa, com sua forma de expressar com termos comuns. Mostram que alguns dados biológicos são apresentados sinteticamente. Todavia, esta linguagem necessitaria da explicação de um adulto para a criança, os termos como "escamas maxilares" e "cabeça côncava e não plana". Destacamos esse fato por dados de pesquisa informarem que o maior público de visita são escolas da educação infantil e do ensino fundamental e famílias com crianças (MACIEL; FACHÍNTERÁN, 2014).

Apesar de ser possível argumentar que para haver a visita de crianças necessitaria de uma companhia responsável (adulto), e este poderia fazer a mediação complementar. Mas no sentindo de mediação e interação com o visitante, as placas colaboram para uma perspectiva minds-on, ou até heards-on, contudo neste caso, poderia ser somente minds-on com objetivos informativos e potencialmente descontextualizado da referência infantil, mas potencialmente contextualizado para relações e temáticas biológicas.

Segundo Ghedin, Ghedin e Fachín-Terán (2016) as placas informativas de espaços não formais conhecidos em Manaus/AM, como o BC, priorizam a informação científica como divulgação da Ciência, mas com capacidade pequena devido a riqueza natural presente e a baixa conservação de algumas delas. Concordamos que a placa informativa é pontual e relacional a um organismo, normalmente, em relação a um ambiente biológico (seguimento de ecossistema, habitat e nicho ecológico), e também que as placas estão malconservadas em algumas ocasiões. Todavia, a informação da placa ser o objeto de divulgação da Ciência só é possível por meio de uma linguagem adequado ao público, e neste sentido, quando este é variado e pluricultural (escolares, turistas e visitantes da região) exige um esforço de adequação e oferta de diversidade de mediação para dialogar com o máximo potencial com público. Por exemplo, placas com adequação de idade, com idiomas diferentes, 
observação de termos regionais, linguagem mesclada de texto e imagem (iconografia e infográfico $)^{7}$.

Em relação a análise pedagógica entendemos como inseparável a intencionalidade e a prática no ato educativo. Assim, sobre os pressupostos epistemológicos predominaram aparentemente o posicionamento empirista sobre o idealista, devido a ênfase na mostra e, a presença da concepção dos autores em que a exposição dos seres vivos formaria o conhecimento, logo, este conhecimento é considerada como externo ao sujeito. Podemos ilustrar com um exemplo:

Este espaço não formal institucionalizado é um dos ambientes favoráveis à aprendizagem do meio ambiente, pois nele encontramos suporte para disseminar a educação ambiental através da educação científica (LEAL; SOUZA; FACHÍN-TERÁN, 2014, p. 7).

O texto em que foi extraído a citação acima possui o contexto da análise de algumas estações do BC por uma disciplina sobre espaços de educação não formal de uma turma de mestrado stricto sensu. A conclusão que a aprendizagem do meio ambiente fica relacionada na educação ambiental e ancorada na educação científica por atividades práticas de sensação com intensão moral conservacionista. A atividade é pedagógica e moralmente estimulante e reflexiva, contudo, não há elementos de educação científica sobre relações conceituais (biológicas) apresentadas no artigo. Logo, a conclusão apresentada está no campo moral, e não científico. O que não quer dizer que sejam impermeáveis, mas neste caso uma não foi a base para a outra, mas a experiência ordinária sincrética do ambiente conduzida levou as conclusões.

O que nos leva a entender que a percepção em ambiente aberto com pluralidades de estímulos sensoriais pode ser valiosa para formação de uma visão holística e direcionada para valores ambientais inicialmente. Posteriormente relaciona-se conceitos científicos num movimento de contextualização, "sincretização" e aplicação das ideias apreendidas para o processo de generalização (conceitualização). Contudo, nesta experiência alcançou a contextualização e iniciou uma "sincretização" a partir da atividade.

Essa percepção empirista pode ser reforçada pelas placas e banners configurados em prestar informação científica. Acreditamos que pode ser balanceado com elementos relacionais para que essa concepção veja que a percepção se desenvolve de forma interdependente com a generalização, recursivamente, numa construção social e individual da realidade (VIGOTSKY, 2007), por meio do diálogo do conteúdo discursivo das placas ou banners com os visitantes sobre tipo de assuntos como questões cotidianas, temáticas contemporâneas e/ou de contexto local ou regional.

No exemplo dado anteriormente ficou claro ao nosso ver que a percepção e a formação de uma visão geral foram confundidas com o processo de aprendizagem

\footnotetext{
${ }^{7}$ Não podemos desprezar que a elaboração de placas assim não basta o layout, mas a tecnologia para manter essa placa em ambiente aberto e resistente ao intemperismo forte amazônico, e como também a manutenção com recursos, periodicamente. Nada obstante, o BC é uma instituição federal ligado a Ciência \& Tecnologia em que estão passando por cortes de verbas a muito tempo.
} 
conceitual $^{8}$ por situar essa aprendizagem como científica pelos autores. Essa sensação pode ser tendenciosa devido na experiência sincrética do acesso das informações dos banners, condução das sensações e fechamento de uma ideia ambiental, desta forma, se torna um todo sincrético, mas sem a coerência e consistência conceitual e proposicional necessariamente. Por isso, que no trabalho poderia ser melhor interpretado como partes de uma experiência cultural voltado para os valores ambientais conservacionistas. Em que não se reduziria em valor, mas pelo contrário, realça o diálogo entre o ambiente, experiência corporal e pensamento conduzido.

De forma geral, os pressupostos psicológicos em relação a discussão dos pesquisadores se afirmavam construtivistas na sua maioria, e em outros trabalhos percebeu a ideia de incrementação, ou seja, pequenos estímulos das informações seriam assimilados. Nesse sentido, os pressupostos filosóficos empiristas tendiam aos pressupostos psicológicos comportamentalistas, e inversamente os pressupostos relacionais tendiam aos pressupostos construtivistas (HEIN, 2006). Assim, percebemos que não há um limite claro de verificação sobre o posicionamento comportamentalista e construtivista em atividades práticas em espaços não formais em si, somente com auxílio da análise da proposta didática. Todavia, há uma aproximação do empirismo ao comportamentalismo, e do diálogo do idealismo com o empirismo ao construtivismo.

\section{Agradecimentos}

Agradecemos a Coordenação de Aperfeiçoamento de Pessoal de Ensino Superior CAPES pelo apoio financeiro via bolsa de estudos. Código - 001. S.D.g.

\section{Considerações}

A educação em espaços não formais contribui para o diálogo da divulgação científica em pesquisas amazônicas do INPA, junto ao público amplo e diversificado como também aos escolares. Podemos avaliar que o BC tem contribuído para educação não formal e a divulgação científica por meio da sua estratégia de autocondução, monitores mirins e Circuito da Ciência devido a continuidade no tempo (a instituição mais antiga na cidade de trabalhos não interruptos) e por ser o objeto de estudo de forma direta ou indireta sobre a temática de educação em espaço não formal de tantas pesquisas.

O potencial de explorar a própria floresta amazônica como recurso educativo proporciona aproximação humana, devido ao distanciamento da vida urbana por refletir sobre seus recursos e como ambiente de habitação para outros organismos, e do próprio ser humano.

Percebemos que apesar da grande maioria de trabalhos sobre a descrição das estações e de sequências didáticas não ocorre uma reflexão epistemológica. Todavia, há um enfoque no empírico-indutivismo, ou seja, os idealizadores creem que por apresentar um ser vivo ao

\footnotetext{
${ }^{8}$ Aqui entendemos que a educação científica se distingue de outras aprendizagens pela leitura da realidade pela ciência, ou seja, a necessidade de compreensão conceitual e proposicional de conceitos e teorias científicas ratificada em alguma tradição de pesquisa.
} 
sujeito o faz adquirir conhecimento, não abordando algum contexto biológico e cultural do conhecimento científico.

As estratégias do Bosque da Ciência não apresentam ainda grupos com tradição de pesquisa e reflexão em relacionar os museus de ciência de perfil amazônico à pesquisa educacional para formação de professores ou mediadores. Diferentes do movimento centros de ciências nacionais em que foi construído essa ponte. Logo, quem faz esse diálogo é o Programa Circuito da Ciência, projeto guia mirim e alguns pesquisadores da Universidade do Estado do Amazonas. Estes últimos trataram da análise dos espaços para enfoque educativo em um organismo, como o peixe-boi, ou quelônios.

Não generalizamos as características aqui expostas e discutidas para todos as instituições de educação não formal da Região Norte. Contudo, percebemos que as características regionais influenciam sensivelmente as atividades e propostas educativas.

Acreditamos serem importantes as pesquisas sobre a percepção dos visitantes e seu impacto para as estações de visitas com base no sócioconstrutivismo, ainda pouco explorado. E compreendemos da necessidade de aproximação dos problemas de pesquisa com a tendência internacional de investigação em aprendizagem informal científica, a qual tem priorizado compreender a experiência humana nos seus variados aspectos da realidade (psicológico, social, linguístico, analítico, cultural) e não somente a dimensão cognitiva humana, e desta forma proporcionar uma formação cidadã e com equidade (NACIONAL RESEARCH COUNCIL, 2009).

\section{Referências}

ABCMC - Associação Brasileira de Centros e Museus de Ciência. Centros e museus de ciência do Brasil 2015. Rio de Janeiro: ABCMC: UFRJ; Fiocruz. Museu da Vida, 2015.

ARAGÃO,T.Z.B. Concepções de ciência presentes na divulgação e práticas institucionais não formais de ensino de ciências. Dissertação (PPG-FE/USP). São Paulo: USP, 2013.

BORGES,R.M.R.; SILVA,A.F.D; DIAS,A.L.M. Cultura e educação científica e tecnológica em centros de ciências no Brasil. In BORGES,R.M.R.; IMHOFF, A.L.; BARCELLOS, G.B. Educação e cultura científica e tecnológica: centros e museus de ciências no Brasil. Porto Alegre: EDIPUCRS, 2015.

BUENO,W.C. Comunicação cientifica e divulgação científica: aproximações e rupturas conceituais. Informação \& Informação, v. 15, n. suplementar, p. 1-12. 2010.

ESHACH,H. Bridging In-school and Out-of-school Learning: Formal, Non-Formal, and Informal Education. Journal of Science Education and Technology, s.l., v. 16, n. 2, p. 171-190, 2007.

FLICK, U. Introdução à metodologia de pesquisa. Porto Alegre: Penso, 2013.

FRANÇA,S.B.; ACIOLY-RÉGNIER,N.M.; FERREIRA,H.S. Caracterização do perfil educacional e de mediação dos museus de ciências da Região Metropolitana do Recife. In: Encontro Nacional de Pesquisa em Educação em Ciências, 8. 2011. Águas de Lindóia, SP. Anais... Águas de Lindóia, SP: 2011. p. 1-12.

GHEDIN, L. M.; GHEDIN, I. M.; FACHÍN-TERÁN, A. Análise das placas informativas em espaços não formais da cidade de Manaus, Amazonas, Brasil. In: S. C. Seiffert Santos \& A. 
Fachín-Terán (Eds.). Temas sobre ensino de ciências em espaços não formais: avanços e perspectivas (pp. 196-209). Manaus: UEA Edições, 2016.

HEIN,G.E. Museum Education Defining Museum Education. In Museum education (pp. 340353), 2006.

JACOBUCCI, D.F.C. Contribuição dos espaços não-formais de educação para a formação da cultura científica. Revista em Expansão, n. 7, p. 57-66, 2008.

LEAL, G. K. S., SOUZA, E. S., FACHÍN-TERÁN, A. Bosque da Ciência: espaço não formal institucionalizado como elemento facilitador no processo de aprendizagem científica através do lúdico. In: Seminário de Educação em Ciências na Amazônia, 4. 2014. Anais... Manaus, AM: PPGEECA/UEA, 2014. p. 1-8.

MACIEL, H. M., FACHÍN-TERÁN, A. O potencial pedagógico dos espaços não formais da cidade de Manaus. Curitiba: Editora CRV, 2014.

MARANDINO, M.; SILVEIRA, R. V. M. Da; CHELINI, M. J.; FERNANDES, A. B.; MARTINS, L. C.; FLORENTINO, H. A. A educação não formal e a divulgação científica: o que pensa quem faz? In: Encontro Nacional de Pesquisa em Educação em Ciências, 4. 2004. Águas de Lindóia, SP. Anais... Águas de Lindóia, SP: 2004.

MARQUES, J. B. V.; FREITAS, D. de. Fatores de caracterização da educação não formal: uma revisão da literatura. Educação \& Pesquisa, São Paulo, v. Ahead of p, p. 1-24, 2017.

MONTPETIT,R. Du science center à l'interprétation sociale des sciences et techniques. In E.H.K.lele (Ed.), olution de la muséologie des sciences (pp. 175-86). Lyon: Presses Universitaires de Lyon/Éditions Multimonde, 1998.

NATIONAL RESEARCH COUNCIL. Learning Science in Informal Environments: People, Places, and Pursuits. (P. Bell, B. Lewenstein, A. W. Shouse, \& M. A. Feder, Eds.). Washington DC: The Nacional Academies Press, 2009.

QUEIROZ, R. M.; TEIXEIRA, H. B.; VELOSO, A. dos S.; TERÁN, A. F.; QUEIROZ, A. G. de. A caracterização dos espaços não formais de educação científica para o ensino de ciências. In: Encontro Nacional de Pesquisa em Educação em Ciências, 8., 2011. Anais ... Águas de Lindóia: ABRAPEC, 2011. p. 1-11.

ROCHA, S. C. B., FACHÍN-TERÁN, A. Guia de visita a espaços não formais amazônicos a partir de uma experiência no Bosque da Ciência. Curitiba: CRV, 2014.

ROCHA, S. C. B., FACHÍN-TERÁN, A. O uso de espaços não formais como estratégia para o ensino de ciências. Manaus: UEA/PPGEECA, 2010.

SEIFFERT SANTOS, S. C.; CUNHA, M. B. da. Os termos de indexação alistados aos espaços de educação não formal num evento de ensino de ciências. In Seminário Internacional de Pesquisa Qualitativa (SIPEQ), 5, 2018. Anais... Foz do Iguaçu: SE\&PQ, 2018. p.1-12. Disponível em: https://sepq.org.br/eventos/vsipeq/documentos/51590930282/11. Acesso em 04 jun. 2018.

STOCKLMAYER, S. M.; RENNIE, L. J.; GILBERT, J. K. The roles of the formal and informal sectors in the provision of effective science education. Studies in Science Education, s.I., v. 46, n. 1, p. 1-44, mar. 2010.

VIGOTSKY, L. S. A formação social da mente (7th ed.). São Paulo: Martins Fontes, 2007. 